World Maritime University

The Maritime Commons: Digital Repository of the World Maritime University

$7-2020$

\title{
Aqueous solution of ammonia as marine fuel
}

Alessandro Schönborn

Follow this and additional works at: https://commons.wmu.se/lib_articles

This Article Open Access is brought to you courtesy of Maritime Commons. Open Access items may be downloaded for non-commercial, fair use academic purposes. No items may be hosted on another server or web site without express written permission from the World Maritime University. For more information, please contact library@wmu.se. 


\title{
Aqueous solution of ammonia as marine fuel
}

\author{
Alessandro Schönborn \\ Maritime Energy Management, World Maritime University, Fiskehamnsgatan 1, 20124 Malmö, Sweden \\ Email: as@wmu.se
}

\begin{abstract}
The ignition of ammonia in aqueous solution was simulated in a two-stroke compression ignition engine model. Zero-dimensional chemical kinetic calculations were used to estimate the ignition timing of fuel air mixtures in Diesel combustion and homogeneous charge compression ignition (HCCI) modes. The fuel consisted of a $25 \% \mathrm{~m} / \mathrm{m}$ aqueous solution of ammonia and pure ammonia for comparison. Ignition was studied by varying the geometric compression ratio of the engine. To ignite ammonia in aqueous solution a minimum compression ratio of 25 was necessary under HCCI combustion conditions, whereas under Diesel combustion conditions a minimum compression ratio of 27 was required. Ammonia containing ammonium nitrite or hydrogen were two potential ammonia derivatives that were shown to enhance aqueous ammonia ignition in the simulations, and allow ignition to take place at a compression ratio of 24 for diesel combustion. When comparing the ignition of aqueous ammonia solution to pure ammonia, the minimum compression ratio necessary to ignite pure ammonia was approximately 24.8 and that for aqueous ammonia 26.7 in diesel combustion. This led to the conclusion that aqueous ammonia is not prohibitively more difficult to ignite than pure ammonia. Ammonia containing ammonium nitrite or hydrogen were found to be potential pilot fuels.
\end{abstract}

Keywords: Ammonia, Aqueous ammonia, Ignition, Ammonium nitrite, Hydrogen

Date received: 26 June 2019; accepted: 25 May 2020

\section{Introduction}

Global Greenhouse Gas (GHG) emissions, of which $\mathrm{CO}_{2}$ emissions constitute the most important part, have led to an increase in global temperatures of $0.85 \mathrm{~K}$ from 1880 to 2012 . GHG emissions have been steadily rising over the last decades, and reached $49 \pm 4.5 \mathrm{GtCO}_{2}-$ equivalent per year in 2010 . In order to limit the global temperature increase to below $2 \mathrm{~K}$, substantial reductions in GHG emissions are required over the next few decades, and zero emissions of $\mathrm{CO}_{2}$ would be required before the end of the 21 st century (IPCC, 2014) [1]. The United Nations have set goals for stabilising GHG emissions under the United Nations Framework Convention on Climate Change (UNFCCC, 1992) [2], and for limiting the temperature increase to below $2 \mathrm{~K}$ in the Paris Agreement (COP 21, 2015) [3]. Shipping was reported to constitute $2.6 \%$ of global $\mathrm{CO}_{2}$ emissions in 2012 (IMO, 2014)[4]. In 2018 the International Maritime Organisation (IMO) adopted the 'Initial IMO Strategy on Reduction of GHG emissions from ships' (IMO, 2018) [5] in order to align itself with the goals of the Paris
Agreement. Aim of this strategy is the reduction of total $\mathrm{CO}_{2}$ emissions by from international shipping by 50 $\%$ by 2050 , by reducing the carbon intensity per transport work by $40 \%$ by 2030 , and by $70 \%$ by 2050 , with respect to the 2008 levels. The decarbonisation of international shipping requires timeliness and effectiveness of the technical measures taken to reduce GHG emissions. Cuts in $\mathrm{CO}_{2}$ emissions need to exceed the reductions possible by the use of low carbon fossil fuels, such as Liquefied Natural Gas (LNG), Ethane or LPG, which are at best around $28 \%$, within about a decade from now. Hydrogen has been proposed as a direct fuel for maritime transportation, but if it is to be stored at high energy density in liquid form, it requires cryogenic temperatures of $20 \mathrm{~K}$ (El Gohary et al. [6] (2014)). Since cryogenic hydrogen is comparatively difficult to store over long periods, due to its gradual boiling, ammonia has been proposed as a potential hydrogen carrier and carbonless energy vector that could provide zero carbon emissions power (Valera-Medina et al., 2018 [7]). Both hydrogen and ammonia will require energy to be produced, and may be associated with life-cycle GHG 
emissions from their production and use, but ammonia has an additional advantage over hydrogen in terms of its physical characteristics. When considering the GPW100 of the fuel substance itself, ammonia has a low GPW100 assumed to be zero for refrigeration applications [8]. Hydrogen has been reported to itself having an estimated Global Warming Potential over 100 years (GWP100) of 5.8 [9], so any release of hydrogen during transportation, storage, or from ships, would have a climate impact. Ammonia can be converted to useful power using established internal combustion engine technology (Kroch, (1945) [10], Gray et al. (1966) [11], Pearsall and Garabedian (1967) [12], Liu et al. (2003) [13]). Its use as a practical fuel for spark ignition engines was demonstrated on a large scale in Belgium in 1943 (Kroch, 1945), where coal gas containing about $50 \%$ hydrogen was used to improve the combustion characteristics of ammonia. Bro and Pedersen (1977) [14] demonstrated the use of ammonia aspirated into the intake air as the main fuel, and ignited it with a pilot injection of diesel fuel. Reiter and Kong (2008)[15] showed that this is possible with biodiesel, and reported a contribution of $95 \%$ of the energy from ammonia. Boretti (2012) simulated the ignition of an anhydrous ammonia engine using hydrogen ignition [16]. Pochet et al. (2017) reported on engine experiments using ammonia and hydrogen mixtures in Homogeneous Charge Compression Ignition (HCCI) combustion mode [17]. Lhuillier et al. (2020) recently reported engine experiments of ammonia and hydrogen mixtures under sparkignition engine conditions [18]. Ammonia has also been demonstrated in modern compression ignition engines in combination with conventional diesel fuel oil, used for ignition (Boretti [19] (2017), and Şahin et al. [20] (2018)). Ammonia may also be used as a fuel for fuel cells, but for the case of Proton Exchange Membrane (PEM) fuel cells, it requires prior conversion to hydrogen via $\mathrm{Ru}, \mathrm{Fe}, \mathrm{Ni}, \mathrm{Co}$ or $\mathrm{NaNH} 2$ catalysts and further reduction of its ammonia content from around 1000 ppm to 0.1 ppm (Miyaoka et al. (2018) [21]). Figure 1 shows that ammonia has a volumetric energy density of $13225 \mathrm{~kJ} / \mathrm{m} 3$, which is similar to that of liquid hydrogen, though ammonia has the advantage of not requiring cryogenic storage.

A disadvantage of ammonia over existing liquid bunker fuels, is that requires pressurisation to $0.43 \mathrm{MPa}$ at standard temperature $(273.15 \mathrm{~K})$ [22]. A further and much more severe disadvantage is its toxicity to humans, and to aquatic life (Merck, 2018)[23]. Human short term exposure limits to ammonia vapour are typically regulated to be as low as $25-50 \mathrm{ppm}$ [8]. However, if ammonia is dissolved in water at $25 \%$ by mass,

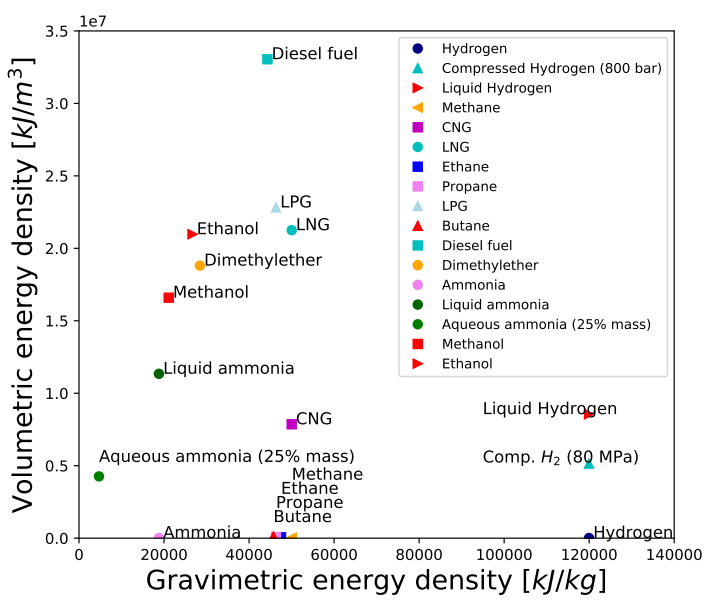

Figure 1: Energy density of various alternative fuels for marine applications.

the solution has a boiling point of $311 \mathrm{~K}$ at atmospheric pressure [22], allowing it to remain liquid in many climates. This could be a considerable advantage over pure ammonia, since the fuel becomes liquid at standard temperature and pressure, and thereby does not require pressurised tanks for containment. This makes the fuel easier to handle, and has the potential of improving its safety, since evaporation of aqueous ammonia solution is slower than that of pure pressurised ammonia when released to the atmosphere. The saturation of liquid ammonia and its mixtures with water is illustrated in Figure 2 (Data from Lemmon et al. [22] (2010)).

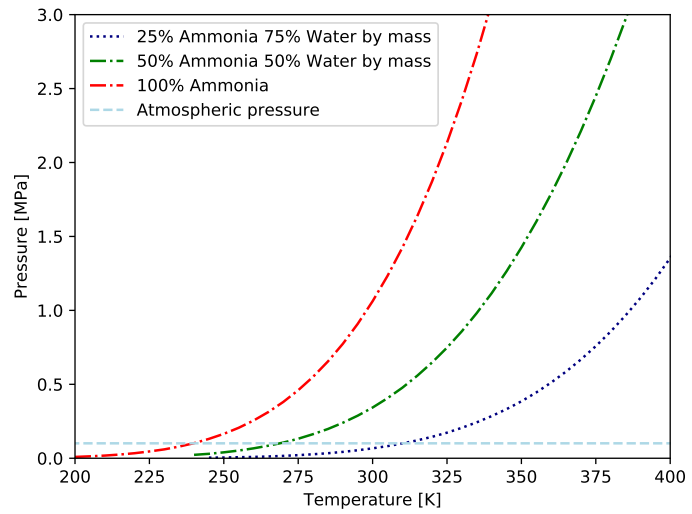

Figure 2: Saturation pressure of liquid ammonia and its mixtures with water.

Figure 2 shows that for a mixture of $25 \%$ ammonia and $75 \%$ water by mass the saturation pressure of the 
liquid lies below atmospheric pressure for temperatures of up to $311 \mathrm{~K}$, allowing it to be stored at atmospheric pressure conditions for temperatures up to this level. In addition to improving safety, pressurising ammonia to the high pressures necessary for injection into an engine becomes simpler, since the bulk modulus of ammonia is significantly increased when absorbed into a liquid aqueous solution, as shown in Figure 3. Its high bulk modulus at atmospheric pressure allows using a liquid fuel injection system.

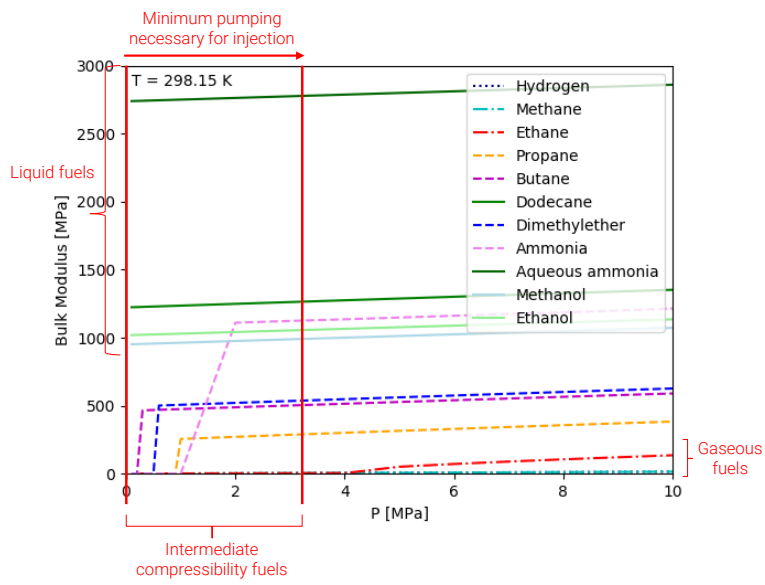

Figure 3: Bulk modulus of potential alternative fuels for marine engines, including $25 \%$ aqueous ammonia by mass.

Despite its potential advantages in terms of its liquid phase at atmospheric pressure, which provides for higher safety levels, the water added to the ammonia may prevent it from being suitably ignited in compression ignition engines. The aim of the current work is to investigate the ignition behaviour of an aqueous solution of ammonia, containing $25 \%$ ammonia by mass in water. Ignition of aqueous ammonia solutions were thus studied under homogeneously premixed and under Diesel combustion mode conditions, to obtain an initial indication of its ability to be ignited, using anhydrous pure ammonia as a basis for comparison. This study employed thermodynamic simulations of compression ignition engine cycles, and included the chemical reaction kinetics necessary to simulate the ignition of vapourised aqueous solutions of ammonia in air.

\section{Engine simulation method}

The engine simulations consisted in a one- and twozone zero dimensional ideal gas reactor simulation for a turbocharged two-stroke compression ignition engine of $500 \mathrm{~mm}$ bore, $2.6 \mathrm{~m}$ stroke, and $2.5 \mathrm{~m}$ connecting rod length. The engine operation was simulated at a constant speed of $100 \mathrm{rpm}$. The dynamic engine simulation code was written in the Python 3.7 programming language, employing the Cantera 2.4.0 software module [24] for the computation of reaction kinetics. A perfectly mixed reactor with a moving wall representing the division between two combustion zones of equal pressure but different temperatures, and a moving wall representing the piston were assumed, as shown in Figure 4.

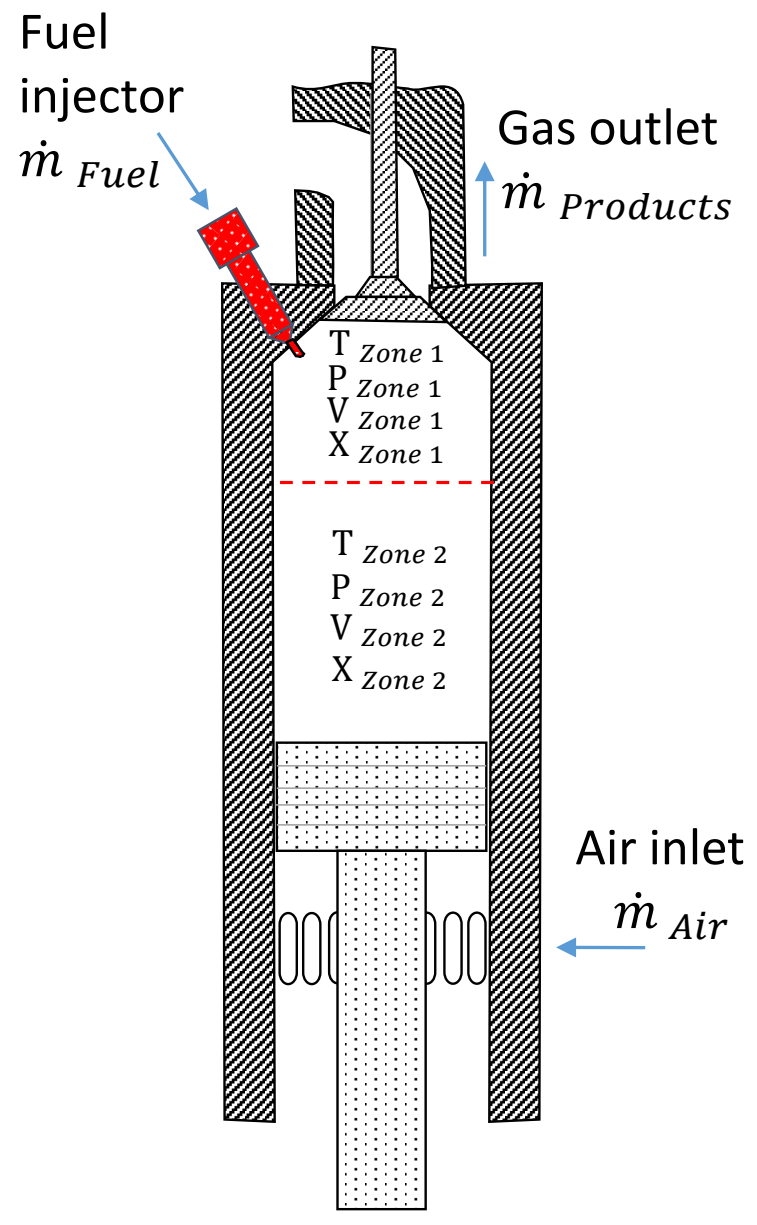

Figure 4: Schematic of the generic two-stroke engine with $500 \mathrm{~mm}$ bore, $2.6 \mathrm{~m}$ stroke, and $2.5 \mathrm{~m}$ connecting rod length.

The compression and expansion of the reactor was simulated using the geometrical relationship of the slider crank equations (Heywood, 1989)[25]. The indicated efficiency of the cycles was calculated as the indicated work divided by the chemical energy contained in the fuel, consisting of the fuel mass $\mathrm{mf}$ and its lower 
heating value LHV, as shown in equation ??:

$$
\eta=\frac{\oint P \cdot d V}{m_{f} \cdot L H V}
$$

The gas exchange processes through the inlet and outlet valves of the engine were simulated by opening the reactor to an inlet and an outlet reservoir during valve opening. The inlet valves were open from 0 ${ }^{\circ}-30{ }^{\circ}$ crank angle of the cycle, and the exhaust valve was open from $330^{\circ}-360^{\circ}$ crank angle. The inlet air reservoir had gas pressure of $0.43 \mathrm{MPa}$, a temperature of $313 \mathrm{~K}$. The outlet reservoir had a pressure of 0.42 $\mathrm{MPa}$. The diesel combustion mode conditions simulated simplified diesel-like conditions, under which the fuel was introduced into the combustion chamber around top-dead-centre (TDC) of the engine cycle, either into the single zone, or if two-zones were used into zone 1 , in which ignition was simulated under stoichiometric conditions. In addition to these diesel combustion simulations, simulations were carried out under homogeneously premixed (HCCI) conditions. In both cases ignition was achieved by compression of the gases. In the homogeneous (HCCI) simulations, a prevapourised mixture of a $25 \% \mathrm{~m} / \mathrm{m}$ ammonia in water was premixed with air, and ignition of the mixture was achieved through compression of the fuel and air charge throughout the cycle. In the diesel combustion mode simulations, the gas initially present in the cylinder consisted solely of $21 \%$ O2 and $79 \% \mathrm{~N} 2$, which was compressed to high temperatures and pressures before an injection of a prevapourised mixture of a $25 \% \mathrm{~m} / \mathrm{m}$ ammonia in water at $300 \mathrm{~K}$ occurred at $3{ }^{\circ} \mathrm{crank}$ angle before TDC and lasted for $15^{\circ}$ crank angle. The chemical kinetic model used to calculate the reactions was that developed by Song et al. (2016) [26], which comprises 34 species, and 204 reactions. This chemical kinetic mechanism developed by Song (2016) has been validated for pressure conditions of 30-100 bar, and temperatures of 450-925 K, which are at the lower end of those representative of marine diesel engines, but currently the state of the art in such schemes. In the case of ammonium nitrite reactions taken place, the chemical kinetic model was augmented by the ammonium nitrite reaction taken from the mechanism of Izato and Miyaki (2018) [27].

\section{Homogeneous Charge Compression Ignition cy- cle results}

First, the ignition of aqueous mixtures of ammonia in air were simulated for homogeneous charge compression ignition (HCCI) conditions using the single-zone combustion model, devised by merging the two combustion zones into one. The influence of the geometric compression ratio on ignition timing was studied in a series of simulations for ammonia and aqueous solution of ammonia. The amount of ammonia was kept constant in both cases, at a fuel to air equivalence ratio of $\Phi=$ 0.175 . The compression ratio was adjusted by adapting the clearance volume at TDC to achieve geometric compression ratios of $24.8,25.8,26.7,27.6$, and 28.3. The scavenging air temperature was $313 \mathrm{~K}$ and the scavenging pressure was $0.43 \mathrm{MPa}$, with the exhaust pressure at $0.42 \mathrm{MPa}$.

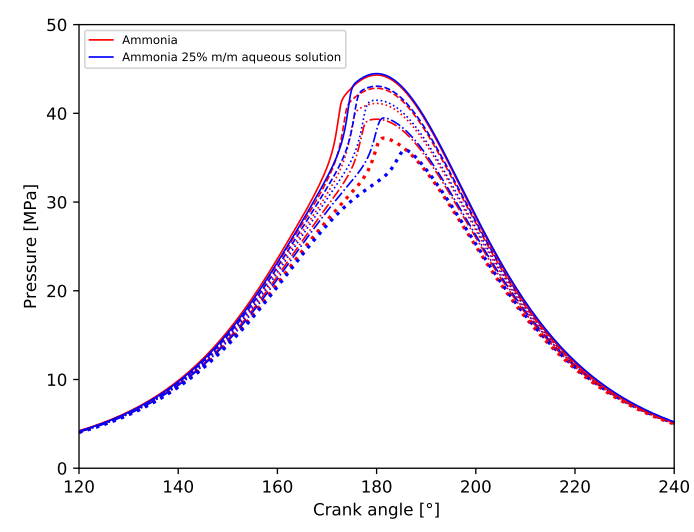

Figure 5: Cylinder pressure for Homogeneous Charge Compression Ignition cycle simulations at fuel to air equivalence ratio of $\Phi=0.175$ compression ratios of 23.8, 24, 25, 27.

Figure 5 shows the cylinder pressure traces versus engine crank angle for HCCI engine simulations for the simulations. As the compression ratio increased, the peak compression pressure of the engine increased, and ignition occurred at an earlier time within the cycle. If a $50 \%$ mixture of ammonia in $50 \%$ water by mass would be used, the cylinder pressure would be expected to lie in between these two lines, which are relatively close together. The thermal efficiencies and indicated mean effective pressures of the engine cycle are shown alongside the compression ratios in Table 1.

Table 1 shows that the optimum compression ratio required to ignite an aqueous solution of ammonia around TDC, was approximately 25:1, when using an intake gas temperature of $313 \mathrm{~K}$, at an intake pressure of $0.43 \mathrm{MPa}$. It should be noted that for zero-dimensional combustion models thermodynamic efficiency and IMEP values are somewhat overestimated, due to the lack of heat transfer and lack of transport and its impact on the chemical kinetics. The efficiency and IMEP values indicated here are solely to be 
used as an indication, since the absolute values found here are higher than what would be achieved in practice.

Table 1: Simulated engine performance at $\Phi=0.175$ various compression ratios (CR) indicated mean effective pressure (IMEP) and thermal efficiency $(\eta)$ of the engine using an HCCI cycle.

\begin{tabular}{ccc}
\hline $\begin{array}{c}\text { CR } \\
{[1]}\end{array}$ & $\begin{array}{c}\text { IMEP } \\
{[k P a]}\end{array}$ & $\begin{array}{c}\eta \\
{[1]}\end{array}$ \\
\hline 24.8 & 521 & 0.556 \\
25.8 & 523 & 0.559 \\
26.7 & 524 & 0.561 \\
27.6 & 525 & 0.562 \\
28.3 & 525 & 0.563 \\
\hline
\end{tabular}

While a detailed estimate of the thermal efficiency is not the aim of this study, it is generally accepted that zero-dimensional modelling as that used in this study yields reasonable accuracy in estimating ignition [28]. Practical Diesel engine break efficiency including frictional losses is currently around 53\%. Practical applications of HCCI combustion do not exist for large marine diesel engines due to problems related to reliably controlling ignition and limiting heat release and pressure rise rates. Partially premixed concepts applied to small engines typically achieve gross indicated efficiencies in excess of $50 \%$ [29]. The highest efficiencies of $61 \%$ presented in this work do not yet account for friction and are around $13 \%$ higher than practical diesel engine efficiencies. The efficiencies should be used here only for the purpose of comparing the performance of different ignition timings with one another, within the context of this work, rather than as absolute practical values. The peak cylinder pressures shown in Figure 5 are unusually high for diesel engine cycles, and although they may theoretically be achievable, they would require significant improvements in the design of piston rings and liners to prevent mechanical wear and scuffing of the cylinder. It should therefore be investigated whether ignition of the charge can be achieved with lower peak cylinder pressures, by increasing the geometrical compression ratio and lowering the scavenging and exhaust pressures.

Figure 6 shows that ignition can be achieved with significantly lower peak cycle pressures when the scavenging pressure and exhaust pressure are reduced, and a high compression ratio of 31 is used. The scavenging pressures used were $0.13,0.23,0.33$, and $0.43 \mathrm{MPa}$, whilst maintaining the original scavenging air temperature of $313 \mathrm{~K}$. Another way of achieving ignition with low peak cylinder pressures, is to lower the compression ratio and increase the scavenging temperature. This was simulated for a geometric compression ratio of 15 , and

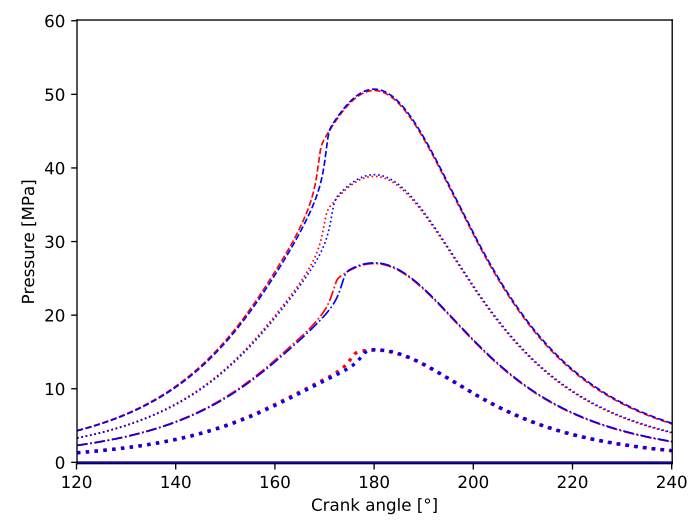

Figure 6: Variation of scavenging pressures $(0.13,0.23,0.33,0.43$ $\mathrm{MPa}$ ) for an HCCI for an HCCI cycle having a high compression ratio of 31 .

scavenging temperatures of $313,338,363$, and $388 \mathrm{~K}$, whilst keeping the scavenging pressure at $0.43 \mathrm{MPa}$.

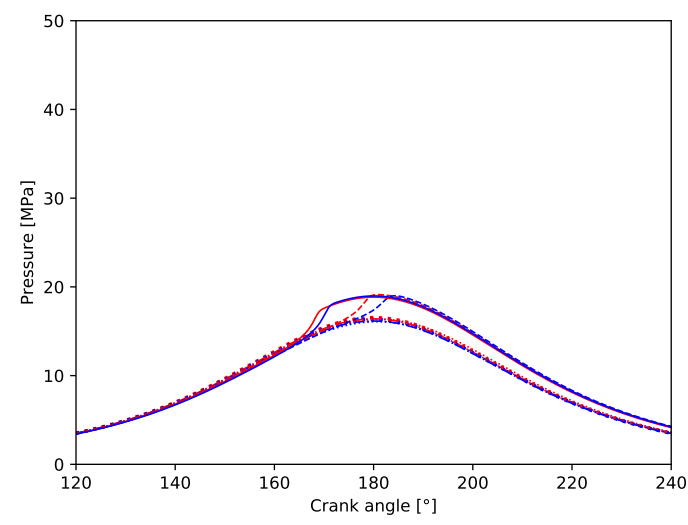

Figure 7: Variation of scavenging pressure for an HCCI cycle with a low compression ratio of 15 .

Figure 7 shows that ignition could be achieved with significantly lower peak cycle pressures when the compression ratio was reduced to 15 , and the scavenging temperature was increased to $363 \mathrm{~K}$ or $388 \mathrm{~K}$.

\section{Diesel cycle results}

The ignition of an prevapourised aqueous mixtures of ammonia in air were simulated for a diesel combustion cycle, using the single-zone combustion model. In these simulations, the fuel was introduced into the combustion chamber at $3^{\circ} \mathrm{crank}$ angle before TDC in 
gaseous state. As for the HCCI simulations, it was important to determine the influence of geometric compression ratio on ignition. The same compression ratios as previously used in the HCCI experiments were used for the diesel cycle simulations. Since the fuel is introduced into the engine cycle at $3^{\circ} \mathrm{crank}$ angle before TDC, it spent less time at high temperatures and pressure, making ignition less likely than for HCCI combustion conditions.

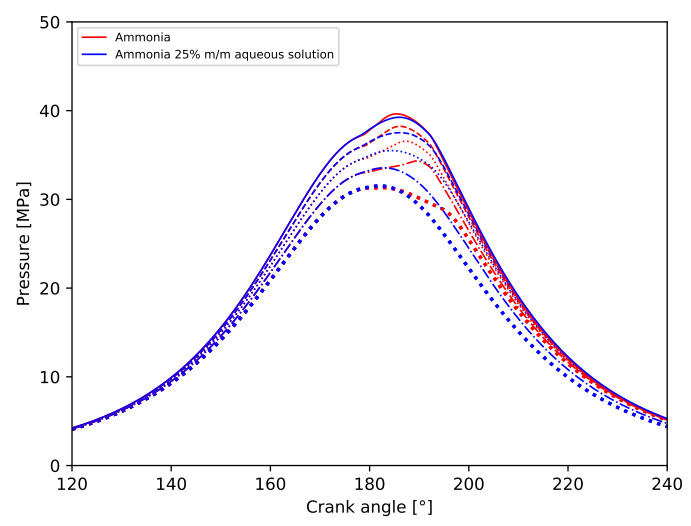

Figure 8: Cylinder pressure for Diesel cycle simulations at compression ratios of 23.8, 24, 25, 27.

Figure 8 shows the cylinder pressures for the Diesel combustion cycle. Whilst ignition was achieved for all compression ratios using pure ammonia as a fuel, the aqueous ammonia solution failed to achieve full combustion for compression ratios lower than 27. The thermal efficiencies of the engine cycle, the IMEP and geometric compression ratio used in the simulations is shown in Table 2.

Table 2. Simulated engine performance at various compression ratios (CR) indicated mean effective pressure (IMEP) and thermal efficiency $(\eta)$ of the engine using Diesel cycle.

\begin{tabular}{ccc}
\hline $\begin{array}{c}\text { CR } \\
{[1]}\end{array}$ & $\begin{array}{c}\text { IMEP } \\
{[k P a]}\end{array}$ & $\begin{array}{c}\eta \\
{[1]}\end{array}$ \\
\hline 24.8 & 174 & 0.174 \\
25.8 & 344 & 0.344 \\
26.7 & 592 & 0.594 \\
27.6 & 609 & 0.611 \\
28.3 & 613 & 0.613 \\
\hline
\end{tabular}

The above simulations highlight the difficulty of igniting aqueous mixtures of ammonia, since engine efficiency of the diesel cycle decreased rapidly below a compression ratio of 27. Aqueous mixtures of ammonia ignited later in the engine cycle, because the water acted as a cold diluent, reducing temperature, as well as the probability of reactant molecules interacting with one another. Aqueous ammonia thus required higher compression ratios to achieve ignition, than pure ammonia did. In order to manage the practical issues posed by such high pressures and temperatures within an engine cycle, mechanical engine components need to be designed differently, to withstand the increased mechanical and thermal loads. The relative differences between aqueous ammonia and pure ammonia, were not extreme though, requiring a rise in compression ratio from 24.8 to 26.7 to overcome the failure of the aqueous ammonia to ignite. The peak cylinder pressures shown in Figure 8 are unusually high for diesel engine cycles, and although they may theoretically be achievable, they are likely to require significant changes in the design of piston rings and liners to prevent mechanical wear and scuffing of the cylinder. It should therefore be investigated whether ignition of the charge can be achieved with lower peak cylinder pressures, by increasing the geometrical compression ratio and lowering the scavenging and exhaust pressures.

Figure 9 shows that ignition can also be achieved in the diesel cycle simulations, with significantly lower peak cycle pressures than in the original simulation. As previously in the HCCI simulations, scavenging pressures of $0.13,0.23,0.33$, and $0.43 \mathrm{MPa}$ were used, whilst maintaining the original scavenging air temperature of $313 \mathrm{~K}$.

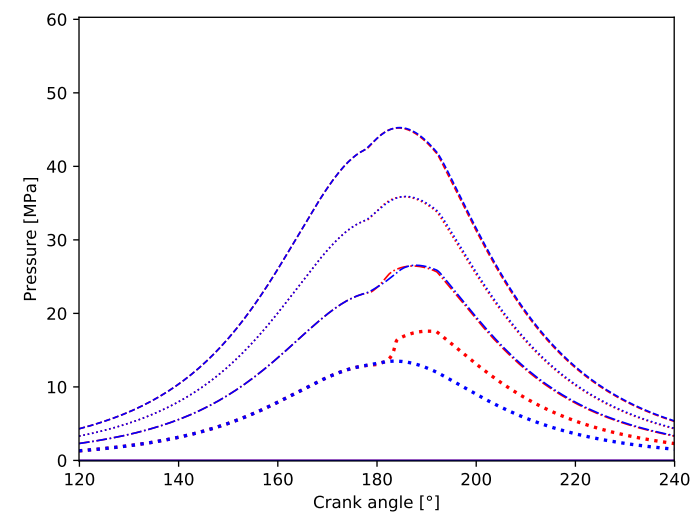

Figure 9: Variation of scavenging pressure in the Diesel cycle for a high compression ratio of 31 .

Ignition might also be achieved with low peak cylinder pressures, if the compression ratio is reduced and 
the scavenging temperature is increased, as shown in Figure 10. This was simulated for a diesel cycle with geometric compression ratio of 15 , and scavenging temperatures of $313,338,363$, and $388 \mathrm{~K}$, whilst keeping the scavenging pressure at $0.43 \mathrm{MPa}$.

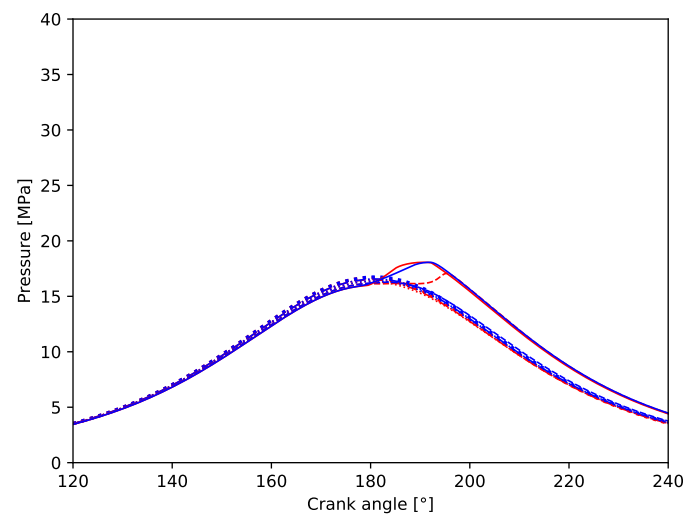

Figure 10: Variation of scavenging temperature for a Diesel cycle with a low compression ratio of 15 .

Figure 10 shows that ignition could be achieved with significantly lower peak cycle pressures when the compression ratio was reduced to 15 , and the scavenging temperature was increased progressively from 313 to $388 \mathrm{~K}$. Increasing the scavenging air temperature, would result in reduced power from the engine at constant displacement, due to the reduced air flow through the engine, and its nitric oxide emissions $\left(N O_{x}\right)$ would also be expected to increase. Thus the use of a pilot injection of a fuel of higher ignition quality would provide a better solution. A pilot injection could be achieved using diesel fuel oil, hydrogen, or ammonia with ammonium nitrite as ignition improving additive.

\section{Influence of water content on ignition}

Although a mixture of $25 \% \mathrm{~m} / \mathrm{m}$ of aqueous ammonia allows for storage of ammonia at atmospheric pressure and temperatures of up to $311 \mathrm{~K}$, lower concentrations of water could also be used. A simple comparison of how mixtures of $100 \%$ ammonia, $75 \%$ ammonia, $50 \%$ ammonia and $25 \%$ ammonia in water, by mass, would behave during ignition. The fuel energy content of the fuel was kept constant by keeping the amount of ammonia injected constant, and progressively increasing the amount of water to vary the ammonia fraction.

Figure 11 shows that an increase in water content retards ignition, which occurs by reducing the reaction temperature during ignition and diluting the reactants.

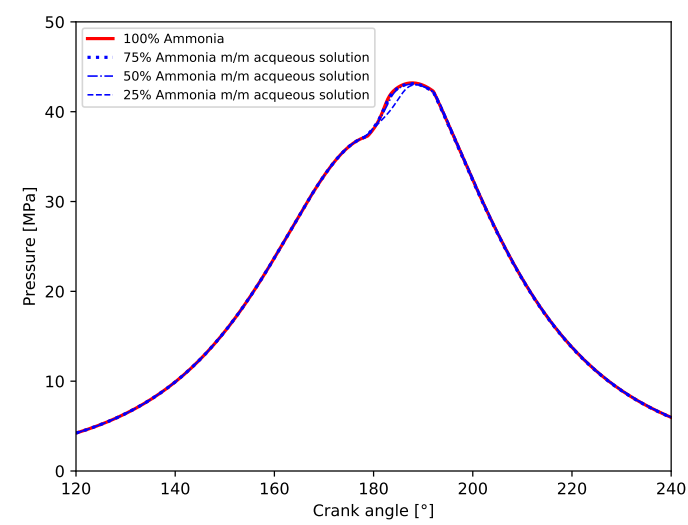

Figure 11: Influence of water content on ignition and combustion pressure during fuel injection in diesel combustion

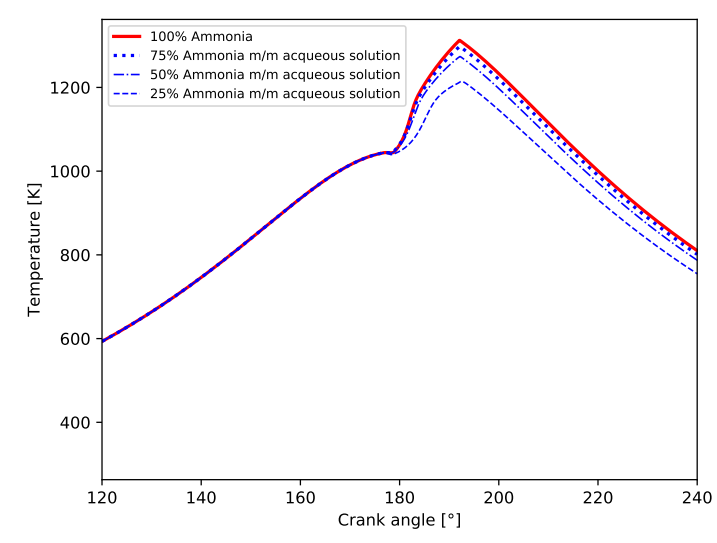

Figure 12: Influence of ammonia water content on temperatures during combustion

The water thus dilutes the ammonia and reduced the reaction temperature during the ignition reaction. Figure 12 shows that this phenomenon increases progressively from pure ammonia to $25 \%$ ammonia in water. The ideal practical water content of aqueous ammonia may be determined first by its ease of storage, as shown in Figure 2, but also by the need to optimise combustion temperatures and finding a balance between $N O_{x}$ emissions formed at higher temperatures, and unburned ammonia emissions formed at lower temperatures.

\section{Hydrogen or Ammonium nitrite as potential igni- tion promoters}

Aqueous ammonia may serve as the raw material for chemical derivatives of ammonia, such as hydrogen or 
ammonium nitrite. These derivatives could be used as reactants that could better initiate ignition than ammonia. Hydrogen addition has been applied to sparkignition engines by Ryu et al. [30], but could also be used as direct injection fuel in compression ignition engines. Hydrogen could be produced from ammonia over Ruthenium catalysts at temperatures below 600-900 K at atmospheric pressure [31]. It could be produced from ammonia on board a vessel and could serve as a carbon free pilot fuel to ignite the main charge of ammonia in an engine. A two-zone engine simulation was used to investigate the ability of a hydrogen pilot injection to ignite a mixture of ammonia and air within the engine. In this simulation both zones of the model contained a homogeneously premixed mixture of aqueous ammonia and air, with hydrogen being injected at $3^{\circ} \mathrm{crank}$ angle before TDC into zone 1 of the reactor model.

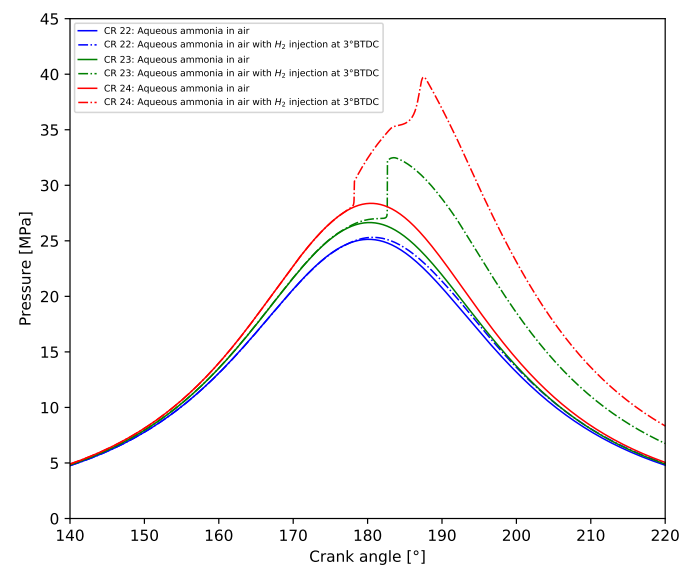

Figure 13: Simulation of ignition of premixed aqueous ammonia and air charge using hydrogen injection

Figure 13 shows that when hydrogen is used as pilot injection fuel, ignition of the homogeneous charge of aqueous ammonia and air were simulated to occur at a compression ratio of 23 . The hydrogen pilot fuel was injected into the ignition zone 1 , which maintained a fuel to air equivalence ratio of unity to better reflect the higher amount of fuel in air surrounding the hydrogen jet. Figure 13 shows that at a compression ratio of 22 the charge failed to ignite. At a compression ratio of 23, only the hydrogen jet was ignited, but the main cylinder charge mixture consisting of aqueous ammonia in air failed to be autoignited. In practice, flame propagation is likely to cause ignition of the entire cylinder at this condition, but in these simulations, there was no heat transfer between reactor zones. At a compression ratio of 24 , the hydrogen jet in the ignition zone ignited first, and subsequently also caused autoignition of the aqueous ammonia and air mixture in the main cylinder charge. This can be seen by the second steep increase in cylinder pressure around $185{ }^{\circ}$ crank angle. These results suggested that autoignition of aqueous ammonia was facilitated by the use of hydrogen as a pilot fuel. As alternative to hydrogen, the ammonia could be reacted with ozone produced from atmospheric air, to produce some ammonium nitrite within the aqueous ammonia, which could be used to increase the autoignition quality of aqueous ammonia as a fuel. This was assumed to be 1 ammonium nitrite molecule within 99 ammonia molecules, and its ignition was simulated by adding the ammonium nitrite reaction from the model of Izato and Miyake (2018)[26] shown in equation 2, to the model of to the model of Song (2016)[25].

$$
\mathrm{NH}_{4} \mathrm{NO}_{2} \rightleftharpoons \mathrm{NH}_{3}+\mathrm{HONO}
$$

The gaseous decomposition reaction constant for ammonium nitrite in the engine was assumed to take the form shown in equation 3 below.

$$
k=2.05 \cdot 10^{21} \cdot T^{-2.591} \cdot e^{-\frac{33984 \frac{J}{k \cdot m o l}}{R \cdot T}}
$$

The results of the simulations simulation can be seen in Figure 14, comparing the injection of aqueous ammonia in diesel combustion mode, with that of aqueous ammonia in which $1 \%$ of ammonia molecules $\left(\mathrm{NH}_{3}\right)$ were replaced by ammonium nitrite $\left(\mathrm{NH}_{4} \mathrm{NO}_{2}\right)$.

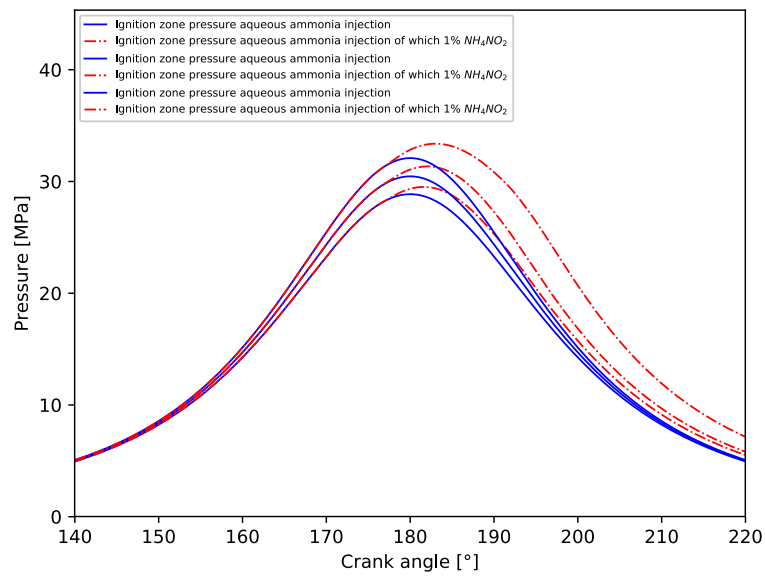

Figure 14: Ignition of aqueous ammonia using $1 \%$ ammonium nitrite within aqueous ammonia fuel under diesel combustion conditions for compression ratios of 24,25 and 26 .

Figure 14 shows that ignition could be achieved for aqueous ammonia containing ammonium nitrite at a 
compression ratio of 24 , while aqueous ammonia without ammonium nitrite failed to ignite. The ignition characteristics of ammonium nitrite will require further detailed study as to their formation, stability, and ignition characteristics and to be validated with experimental ignition experiments, but could provide a potential method for the ignition of aqueous ammonia at lower pressures and temperatures.

\section{Summary and conclusions}

The ignition of prevapourised mixtures of $25 \%$ ammonia $\mathrm{m} / \mathrm{m}$ in water was investigated using chemical kinetic models of HCCI and diesel combustion cycles. The influence of geometric compression ratio on water content in the fuel were studied in a series of simulations. The simplified thermodynamic and chemical kinetic calculations showed that aqueous ammonia does not require a very much higher compression ratio or temperature for ignition than anhydrous ammonia. It was found that both HCCI and diesel combustion cycles, required geometric compression ratios in excess of 25 to achieve ignition of aqueous ammonia solution under HCCI conditions, and compression ratios in excess of 27 to achieve ignition or of aqueous ammonia solution in Diesel combustion mode. In diesel combustion mode, the difference in compression ratio necessary for ignition of pure anhydrous ammonia and an aqueous solution of ammonia, was 24.8 to 26.7 . This relatively small change leads to the conclusion that an aqueous mixture of ammonia may not be much less suitable than pure anhydrous ammonia as a fuel for compression ignition engines. While both aqueous ammonia and anhydrous ammonia are known to be notoriously difficult to ignite, and while initial generations of ammonia powered engines are likely to use a separate source of ignition, such as a pilot injection of a fuel of higher ignition quality, such as diesel fuel oil, biodiesel, hydrogen, or ammonia containing ammonium nitrite, these computations indicate that the ignition characteristics of aqueous ammonia are not significantly worse than those of anhydrous ammonia, on a relative basis, and that both could be considered as future fuels. Aqueous ammonia solutions may be able to improve health and safety concerns for ammonia, as well as removing the need for pressurised tanks. The advantages of both anhydrous ammonia and aqueous ammonia over fossil diesel fuel are of course their potential to be carbon neutral. It has the added advantage over hydrogen, that it can be stored under less extreme cryogenic conditions than liquid hydrogen $(20 \mathrm{~K})$, and in the case of aqueous ammonia, can be stored at atmospheric pressure and typi- cal ambient temperatures. Ammonia has the further advantage over hydrogen in that the fuel itself, once produced, has a lower global warming potential [9] measured over 100 years (GWP100), of around zero, compared to hydrogen, which has been stated as possibly having a GWP100 of 5.8 [6]. This may be an advantage for unintended release of fuel during production, transport, storage or use of the fuel. Further work will be necessary to assess the ignition and combustion characteristics of aqueous ammonia in compression ignition engines, and further work will be necessary to evaluate the safety and environmental risks posed by these fuels. The practical emissions of $N O_{x}$ will need to be determined under realistic engine conditions, and kept below their legislated level. The addition of water to ammonia, may be beneficial in lowering $N O_{x}$ emissions, by lowering combustion temperatures. Practical tests will be necessary to confirm the ignitability of aqueous ammonia mixtures, and the concentration of unburned ammonia in the exhaust gases. Unburned ammonia in the exhaust gases may serve to reduce $N O_{x}$ in a selective catalytic reduction (SCR) reactor, and may prove useful in reducing $N O_{x}$ emissions.

\section{References}

1. International Panel on Climate Change (IPCC) [Core Writing Team, Pachauri R K and Meyer L A (eds.)]. 2014. Climate Change 2014: Synthesis Report. Contribution of Working Groups I, II and III to the Fifth Assessment Report of the Intergovernmental Panel on Climate Change. IPCC, Geneva, Switzerland, $151 \mathrm{pp}$.

2. United Nations. United Nations Framework Convention on Climate Change (UNFCC). Rio de Janeiro, Brazil: 1992.

3. Conference of Parties (COP) 21. The Paris Agreement. 2015.

4. International Maritime Organization (IMO). 2014. Third Greenhouse Gas Study.

5. International Maritime Organization (IMO). 2018. MEPC304(72).

6. El Gohary, M.M., Welaya, Y.M.A. \& Saad, A.A. The use of hydrogen as a fuel for inland waterway units. J. Marine. Sci. Appl. 13, 212-217 (2014). Doi.org/10.1007/s11804-014-1243-0

7. Valera-Medina A, Xiao H, Owen-Jones M, David W I F, Bowen P J (2018) Ammonia for power. Prog. Energy Combust. Sci. 69: 63-102.

8. UNEP (2014). Montreal Protocol on Substances that Deplete the Ozone Layer. UNEP 2014 report of the refrigeration, air conditioning and heat pumps technical options committee. ISBN: 978-9966-076-09-0. 
9. IPCC (2007). Contribution of Working Group I to the Fourth Assessment Report of the IPCC. Assessment Report, 2007. p.215.

10. Kroch E. (1945). Ammonia - a fuel for motor buses. J. Inst. Pet. 31: 214-223.

11. Gray, J., Dimitroff, E., Meckel, N., and Quillian, R., Ammonia Fuel - Engine Compatibility and Combustion, SAE Technical Paper 660156, 1966, Doi.org/10.4271/660156.

12. Pearsall, T. and Garabedian, C., Combustion of Anhydrous Ammonia in Diesel Engines, SAE Technical Paper 670947, 1967, Doi.org/10.4271/670947.

13. Liu, R. Ting, D. S.-K., Checkel, M. D., Ammonia As A Fuel For SI Engine. SAE paper 2003-01-3095 (2003).

14. Bro, K. and Pedersen, P., Alternative Diesel Engine Fuels: An Experimental Investigation of Methanol, Ethanol, Methane and Ammonia in a D.I. Diesel Engine with Pilot Injection, SAE Technical Paper 770794, 1977, Doi.org/10.4271/770794.

15. Reiter, A.J., \& Kong, S.-C., Demonstration of Compression-Ignition Engine Combustion Using Ammonia in Reducing Greenhouse Gas Emissions. Energy \& Fuels 200822 (5), 2963-2971. DOI: 10.1021/ef800140f

16. Boretti, A. A. (2012). Novel heavy duty engine concept for operation dual fuel H2-NH3. DOI: Doi.org/10.1016/j.ijhydene.2012.01.091.

17. Pochet M, Truedsson I, Foucher F, Jeanmart H, Contino F. Ammonia-Hydrogen blends in Homogeneous-Charge Compression-Ignition Engine. SAE Tech Pap 2017; 2017-24-0087. Doi:10.4271/2017-24-0087.

18. Lhuillier, C., Brequigny, P., Contino, F., \& Mounaïm-Rousselle, C. (2020). Experimental study on ammonia/hydrogen/air combustion in spark ignition engine conditions. Doi.org/10.1016/j.fuel.2020.117448

19. Boretti, A., (2017). Novel dual fuel dieselammonia combustion system in advanced TDI engines. International Journal of Hydrogen Energy 42 (2017) pp. 7071-7076.

20. Şahin, Z., Akcanca, İ.Z. \& Durgun, O., (2018). Experimental investigation of the effects of ammonia solution $(\mathrm{NH} 3 \mathrm{OH})$ on engine performance and exhaust emissions of a small diesel engine. Fuel 214 (2018) pp.330-341.

21. Miyaoka, H., Ichikawa, T., \& Kojima, Y., (2018). Highly purified hydrogen production from ammonia for PEM fuel cell. International Journal of Hydrogen Energy 43 (2018) 14486-14492.

22. Lemmon E W, Huber M L, and McLinden M O, (2010) NIST Standard Reference Database 23, Version
9.0.

23. Merck (2018). Ammonium hydroxide. Safety data sheet.

24. Goodwin, D. G., Speth, R. L., Moffat, H. K., Weber, B. W., Cantera: An object-oriented software toolkit for chemical kinetics, thermodynamics, and transport processes. Version 2.2. 1. www.cantera.org, 2018. Version 2.4.0. doi:10.5281/zenodo.1174508 2018 .

25. Heywood J B (1989) Internal Combustion Engine Fundamentals. McGraw-Hill, NewYork.

26. Song $\mathrm{Y}$, Hashemi $\mathrm{H}$, Christensen $\mathrm{J} \mathrm{M}$, Zou C , Marshall P , Glarborg P (2016) Ammonia oxidation at high pressure and intermediate temperatures, Fuel 181:358-365. DOI: Doi.org/10.1016/j.fuel.2016.04.100.

27. Izato, Y., \& Miyake, A. (2018). Detailed kinetic model for ammonium dinitramide decomposition. DOI: Doi.org/10.1016/j.combustflame.2018.09.013.

28. Hammond Z M, Mack J H, Dibble R W (2014) Effect of hydrogen peroxide addition to methane fueled homogeneous charge compression ignition engines through numerical simulations. Int. J. Engine Res. 17:209-220.

29. Liu, H., Tang, Q., Yang, Z., Ran, X., Geng, C., Chen, B., Feng., L., Yao, M. (2019). A comparative study on partially premixed combustion (PPC) and reactivity controlled compression ignition (RCCI) in an optical engine Doi.org/10.1016/j.proci.2018.06.004

30. Ryu, K., Zacharakis-Jutz, G. E., \& Kong, S. (2014). Performance enhancement of ammonia-fueled engine by using dissociation catalyst for hydrogen generation Doi.org/10.1016/j.ijhydene.2013.11.098

31. Lamb, K. E., Dolan, M. D., \& Kennedy, D. F. (2019). Ammonia for hydrogen storage; A review of catalytic ammonia decomposition and hydrogen separation and purification. Doi.org/10.1016/j.ijhydene.2018.12.024. 